\title{
Social Implications of the Social Media Use by Students with Disabilities at the University of Jordan: Facebook as a Model
}

\author{
Hisham A. Almakanin ${ }^{1}$, Ali M. Alodat ${ }^{2 *}$, Asem M. Al-Bakkar ${ }^{3}$, Haifa S. Batarseh ${ }^{4}$ \\ ${ }^{1,4}$ Hashemite University, Zarqa, Jordan. \\ ${ }^{2}$ Yarmouk University, Irbid, Jordan. \\ ${ }^{3}$ Al-Balqa Applied University, Alsalt, Jordan. \\ *ali.alodat@yu.edu.jo
}

\begin{abstract}
This study aimed to measure the benefits of using the social media website as perceived by students with disabilities at the University of Jordan. The sample consisted of 150 students with disabilities and used a 5-point Likert scale to rank the perceived benefits on a 12-item survey. On average, the students indicated that using social media websites provided a moderate level of social benefits. In contrast, the students indicated that social media websites provided a high level of social benefit for increasing the number of new friends, deepening their relationship with others who have a disability or who are concerned with disabilities, and identifying societal attitudes toward disability and disability support services.
\end{abstract}

Keywords

Students with Disabilities, Social Media, Social Implications, Higher Education.

\section{Introduction}

During the past few years, social media websites have significantly impacted daily communication patterns and knowledge exchanges worldwide. The spread of social media has allowed subscribers to create private social networks where they can link electronically to one another across the world and share similar interests and hobbies. Such electronic networks play a vital role in influencing members' beliefs, daily habits, and cultural traditions (Al-Alami, 2011). They have become a significant determinant for shaping members' thoughts and behaviors and have disrupted traditional communication patterns and social reality, particularly for youth (Al-Jallad, 2014). Social media is pushing people toward a new age of global interaction and communication, freedom of expression, and information access that transcends their traditional borders and barriers. Social media sites such as Facebook, Twitter, and Instagram are not merely information sites that people view occasionally. Instead, they are an integrated part of many individuals' daily lives and provide different user gratification (AlHayes, 2015).

Facebook was launched by Mark Zuckerberg in 2004 and is one of the largest social media websites in terms of membership (Ahmad, 2011).
Facebook has over 750 million subscribers, most of whom are youth. Data published on the Statistics Facebook website indicate that $66 \%$ of the Jordanians have Facebook accounts. Jordanian youth have $41 \%$ of these accounts; most of these youth are between 18 and 23 years old (Facebook website, 2017) when they enroll in universities. Consistent with the data posted on the Facebook website, A'abed (2012) also found that Facebook accounts for $79.9 \%$ of the students' social networking activities, and Al-Saqer and Hendawi (2016) found high usage of social media sites by adolescents. Similarly, Al-Oteibi's study (2018) indicated that Facebook usage has spread to $77 \%$ of the students. In addition to the number of users, time spent on social media platforms is an essential factor influencing communication patterns. Al-Masri's study (2010) indicated that $30 \%$ of the social media users spent less than one hour, $22 \%$ spent one to two hours, and $26 \%$ spent more than three hours a day on social media sites. Al-Ahmar's study (2011) showed that social media usage ranged between three and four hours daily. A'abed (2012) found that $40.45 \%$ of university students in the study spent one to three hours a day on social media. Al-Fadhil's study (2013) showed that King Saud University's students used social media two and four hours daily. An important motive for students to use 
social media might be explained by the uses and gratifications theory, based on the selective exposure principle, a sociology concept. According to the uses and gratifications theory, people select information resources that gratify their needs, particularly social and psychological needs (Kardash, 2005). According to the selective exposure principle, individuals voluntarily expose themselves to information resources that match their interests, desires, and thinking patterns. In their study, Urista and Day (2014) asserted that students use social media to gratify their personal needs and desires to communicate with others. These sites allow for rapid communication of content to others, whether they be few or many. Social media platforms facilitate exchanging information, views, and ideas and promoting selfefficacy, improved communication skills, and increased motivation to communicate (Boyd \& Ellison, 2008).

\section{Literature Review}

Findings from several studies about social media use in general and Facebook, in particular, revealed that these sites increased social relationships by expanding opportunities to share news and ideas, remain informed about one another's personal lives, respond to postings, send compliments, and explore interests. Such actions helped strengthen existing friendships, increase the number of friends who share similar interests, remove psychological and social barriers between the genders, and meet people across gender lines. Social media also provided long hours of entertainment in online games (Abu Sa'ileek, 2012; Al-Zboun \& Abu S'aileek, 2014; Young, 2011). Young (2011) conducted an Internet opinion poll of students from Sydney University. These students indicated that Facebook networks enhanced their existing friendships by expanding their traditional communication modes, such as telephones and face-to-face contact. Besides, Facebook allowed for effective communication with larger groups of acquaintances, which, in turn, contributed to their social capital. Brown and Yang (2013) found similar correlations between the reasons for and the level of Facebook use by secondary and university students. Also, they found that the Facebook network enhanced social adaptation within the university environment.
These results were supported by Junco (2013), who found that certain Facebook activities contributed to positive social relationships among the students. Ellison (2014) found that Facebook contributed to positive social interaction by providing essential background information to introduce people to one another and form relations with the friends' group.

Al-Hayes (2015) expanded on these studies and examined the effects of social media interactions on specific aspects of students' personalities at Sultan Qaboos University, such as social awareness, self-development, and social capital development. The findings revealed that social media usage (a) fostered understanding and civilized communication with others, (b) promoted values of volunteerism and social participation, (c) reduced forms of social discrimination, and (d) supported humanitarian interactions across different nationalities. The study by Bader (2015) indicated that the most important social effects of social media usage for students at Gulf States University in the United Arab Emirates were: increased exposure to other cultures, increased vocabulary, and increased satisfaction with communicating with old friends.

Social media's impact on the social, psychological, educational, and cultural aspects of people's lives is not always positive (Al-Jallad, 2014; Al-Zboun \& Abu S'aileek, 2014). There also are negative aspects to social media, especially in light of the absence of control systems to monitor what may be aired. These negative aspects are a concern. Uncensored falsifications, propaganda, violent content, and vilifications at the personal and societal levels influence negative thoughts and behaviors and create risks for community members, in general, and youth, in particular. Studies are needed to understand these positive and negative effects and determine if and how social media sites should be controlled.

Many youths who have disabilities use social media (Abu El-Robb, 2015) even though these websites often are designed for people without disabilities (Jaeger, 2009). It may be that these youth are attracted to social media sites because they provide relatively easy access to social networks. By comparison, face-to-face social interactions may be more difficult for the youth to 
initiate because of the physical limitations associated with their disabilities (Al-Rajabi \& AlRimawi, 2016). In addition, because the youth do not need to disclose their disability, they may find that social media help mitigate societal biases that limit their interactions with others (Abu El-Robb, 2015).

Heasley's study (2010) showed that social media networks opened the gates for individuals with disabilities. The networks afforded greater social access for these individuals, allowed them to form fruitful friendships, minimized negative perceptions directed against them, and reduced isolation by creating communication channels to large numbers of people. Katrina and Nessa (2012) focused their study on students' social media experiences with learning disabilities. Their results indicated that social media assisted these students with initiating and maintaining friendships. Asuncion, Budd, Fichten, Nguyen, Barile, and Amsel (2012) compared the accessibility of various social media platforms for post-secondary age students with disabilities. The results indicated that these students accessed YouTube more frequently than other websites and that Windows Live Messenger was the most accessible website.

Several researchers examined the use of social media by people with specific disabilities. Soderstrom and Ytterhus (2010) found that people with visual impairments accessed social media sites less frequently than those with other disabilities. These sites' technical operations were based on visual displays and thus did not accommodate the needs of people with visual impairments. Those people who were blind required assistive technology to access social media sites. Abu Al-Robb (2015) conducted a study of individuals with disabilities in the Kingdom of Saudi Arabia (KSA) and found that they benefited socially, cognitively, and psychologically, but not professionally when using social media. Those individuals with visual impairments who were 35 years of age or older, and who had only a secondary education level benefitted the least from social media.

Abdul Hamid, Imam, and Aziz (2015) studied the social media usage of 200 youth with total hearing loss. The youth were 12 to 18 years old and attended preparatory and secondary schools in
Cairo and Monoufia. The researchers found that these youth used Facebook most frequently, followed by YouTube and Twitter; 51\% of the youth used social media sites more than once a day, and $46 \%$ spent 1 to 2 hours a day on these sites. The researchers also found a positive correlation between social media use by these youth and their degree of gratification. The use of social media did not appear to affect their other social relationships.

Other researchers focused specifically on the use of social media by university students with disabilities. For example, Lewthwaite (2011) examined the social media networks of students with disabilities on university campuses in the United Kingdom and obtained results consistent with Heasley's (2010) findings. The networks provided significant support for their new educational experiences, promoted interactions between students with and without disabilities, and facilitated change in disability perceptions. These interactions minimized prejudices directed toward students with disabilities, created opportunities for them to express positive feelings about their capacities and reduced the adverse effects of disability status. The current study expands upon the work of Lewthwaite (2011) and others (Bader, 2015; Al-Hayes, 2015; Al-Ahmar, 2011; Al-Masri, 2010; Yang \& Brown, 2013) by exploring the benefits of social media usage from the perspective of students with disabilities specifically at the University of Jordan. No studies could be found that gathered the perspective of university students with disabilities at Jordanian or Arab universities regarding social media usage benefits. Furthermore, this current study is distinguished by its sample, which included students with auditory, visual, physical, and health disabilities. Such research is essential for framing policies at the University of Jordan that address students' learning and social support needs with various disabilities.

\section{Study Problem and Research Questions}

The University of Jordan has more students with disabilities than any other university in Jordan. According to data collected from the Deanship of Student Affairs at the University of Jordan (2017), 500 students had a visual, auditory, physical, or 
health disability. Nevertheless, no research existed to help inform administrators and faculty at this university or any other university in Jordan about how social media, specifically Facebook, could be used to support student success. Thus, this study sought to answer the following questions:

- What are the perceptions of students with disabilities in the University of Jordan about the perceived benefits of social media usage?

- Do students with different disabilities at the University of Jordan have statistically significant differences in perceptions about the perceived benefits of social media usage?

\section{Study Rationale and Significance}

This study is the first in Jordan and perhaps only one of the few within the Arab world, as far as the researchers could find, that examines social media usage by university students with varying disabilities. Thus, the results contribute to the Arab and international literature about university students' electronic communications practices with disabilities. This current study may catalyze additional studies that evaluate the implications of social media usage on the learning and social development of Jordanian and Arab university students with disabilities. It is hoped that this study's results provide foundational knowledge about disability supports that should be incorporated into university training and counseling programs.

\section{Methods}

\section{Study Sample}

The study population consisted of all male and female students with disabilities who were enrolled at the University of Jordan during the first semester of the academic year in 2017/2018 $(\mathrm{N}=500)$. According to admission and registration data provided by the Student Affairs Deanship, these students had auditory, visual, physical, or health disabilities. A random stratified method was used to select 150 of these students to participate in the study. The sample consisted of 86 males and 64 females aas shown in Table 1.
Table 1. Distribution of the study sample participants

\begin{tabular}{ccc}
\hline Disability & N & Percentage \\
\hline Auditory & 40 & $27 \%$ \\
Visual & 68 & $45 \%$ \\
$\begin{array}{c}\text { Physical and } \\
\text { Health }\end{array}$ & 42 & $28 \%$ \\
Total & 150 & $100 \%$
\end{tabular}

\section{Study Instrument}

Since a standardized survey tool could not be found, the researchers constructed a survey instrument specifically for this study. First, they reviewed the literature about electronic social media and the effects of social media usage, particularly those by Abu Al-Robb (2015), AlZboun, and Abu Su'aileek (2014), and Awawdeh (2013). The researchers then interviewed some social media users about their social experiences. Based on the literature and social media users' information, the lead researcher constructed a 12item survey tool and a five-point Likert scale using the following gradients: 5= always; $4=$ often; $3=$ sometimes; $2=$ rarely; $1=$ never $=1$ grade.

Validity. The researchers established apparent validity for the instrument. Apparent validity is a type of content validity and involves arbitrators (Melhem, 2017). Nine faculty members from Hashemite University and Al-Balqa' University special education, psychology and counseling, sociology, and measurement, served as the arbitrators. They reviewed the 18 items in the draft version of the instrument to determine alignment with the study objectives and clarity for content validity. The faculty members recommended paraphrasing some items, deleting other items, and combining some items to achieve a $100 \%$ agreement between the items and the study objectives. The final version of the instrument contained 12 items.

The researchers then established construct validity. They obtained the correlation coefficients to determine each item's overall relatedness; correlation coefficients ranged between 0.19 and 0.58 .

Reliability. To assess instrument reliability, the researchers conducted Cronbach Alpha analysis using scores of 20 male and female students from 
outside the study sample. The researchers obtained a Chronbach alpha of $\mathrm{r}=0.78$,

\section{Procedures}

The researchers met with Students at the University of Jordan to establish collaboration for the research. The researchers then visited the offices and clubs for students with disabilities at the University of Jordan to explain the study's objective and distribute the instrument to the study participants. A sign language specialist translated the instrument items for students with hearing loss. The items were read to students who were blind. The responses of these students were recorded on the corresponding boxes of the instrument items. The remainder of the participants completed the survey independently.

The researchers collected and analyzed the responses using descriptive statistics to identify the perceived benefits of social media usage by students with disabilities at the University of Jordan. The researchers calculated the means (M) and standard deviations (SD) to answer the first question. Then they calculated the degree of effect of social media site usage on social aspects by subtracting the minimum score (1) from the maximum (5) score, then divided the results by three to obtain the range of scores for three levels: low, moderate, and high. Accordingly, scores between 1.00 and 2.3 were labeled as providing a low level of benefit, those between 2.34 and 3.66 were labeled as providing a moderate level of benefit, and those between 3.67 and 5.00 were labeled as providing a high level of benefit. To substantiating the reliability of the instrument.

determine differences in perceptions of benefits between groups, the researchers conducted a oneway ANOVA and Scheffe's test.

\section{Results}

The researchers used the means and standard deviations of the sample participants' responses on the scale of the social implications to measure university students' perceptions with disabilities about the benefit of social media usage. As shown in Table 2, the social implications level of the social media website use of students with disabilities was generally moderate $(\mathrm{M}=3.64$, $\mathrm{SD}$ $=0.19$ ). Mean scores at the high level were obtained for seven items ( $M=3.75$ to 4.76); Mean scores at the moderate level were obtained for four items ( $\mathrm{M}=2.75$ to 3.38), and a means score at the low level was obtained for one item $(\mathrm{M}=$ 1.72). The item that obtained the highest mean score was "Social media provides me chances to expand my social relations by increasing introduction to new friends" $(\mathrm{M}=4.76, \mathrm{SD}=$ 0.43). The item with the second highest mean score was "Social media helps me to deepen my relations with other people who have the same disability or share similar interests" $(\mathrm{M}=4.62$, SD $=0.49$ ). The item with the lowest mean score was "Social media allows me to revive and strengthen my old social relations with colleagues, relatives or friends" $(\mathrm{M}=1.72, \mathrm{SD}=0.69)$.

Table 2. Descriptive statistics of perceived social benefits resulting from social media use

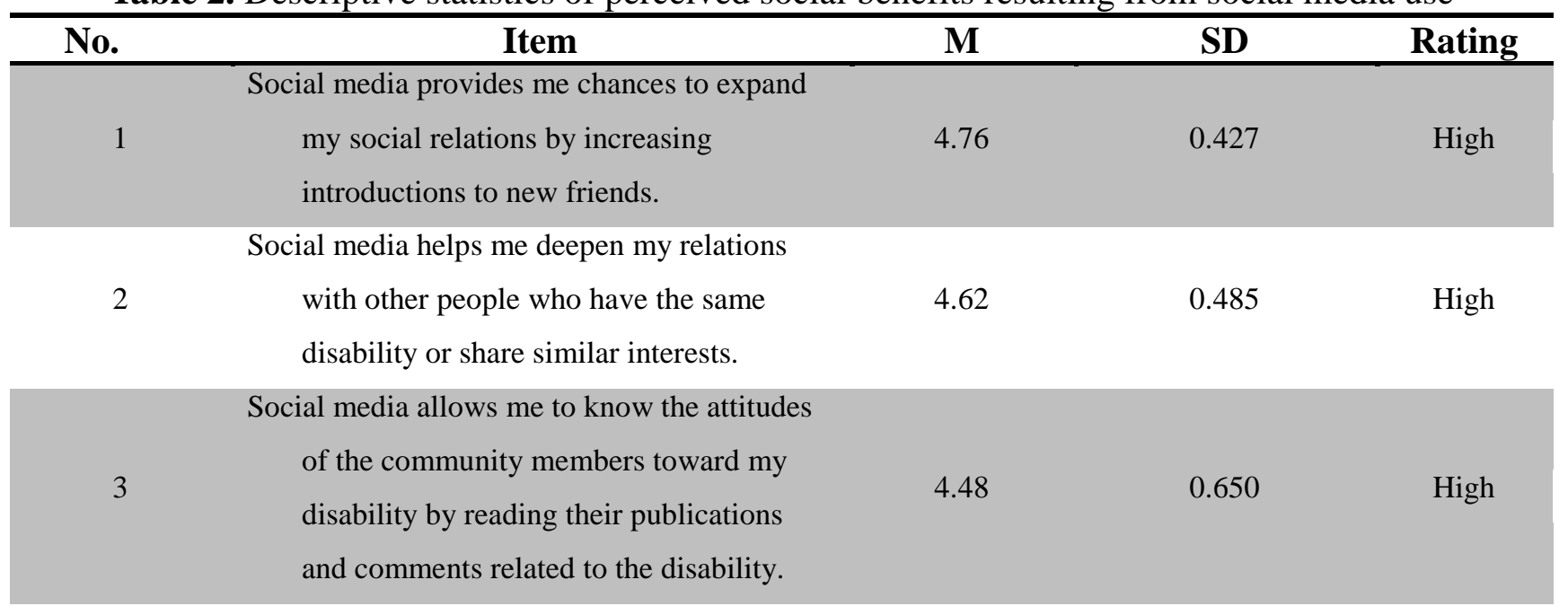




\begin{tabular}{|c|c|c|c|c|}
\hline 4 & $\begin{array}{l}\text { Social media allows me to know the services } \\
\text { provided by civil society institutions in } \\
\text { disability and means to access them. }\end{array}$ & 4.38 & 0.486 & High \\
\hline 5 & $\begin{array}{l}\text { Social media provides me chances to connect } \\
\text { with others and to interact with them } \\
\text { virtually in their social activities }\end{array}$ & 4.38 & 0.690 & High \\
\hline 6 & $\begin{array}{l}\text { Social media enhances opportunities to build } \\
\text { social support groups, including family } \\
\text { and special interest groups. }\end{array}$ & 3.76 & 0.658 & High \\
\hline 7 & $\begin{array}{l}\text { Social media facilitates my access to other } \\
\text { people who are very difficult to approach } \\
\text { because of geographic distances or } \\
\text { because of the inability to meet } \\
\text { physically. }\end{array}$ & 3.75 & 0.824 & High \\
\hline 8 & $\begin{array}{l}\text { Social media provides me chances to reduce } \\
\text { the negative social constraints I face. }\end{array}$ & 3.38 & 0.690 & Moderate \\
\hline 9 & $\begin{array}{l}\text { Social media provides me the opportunity to } \\
\text { display my social self through the number } \\
\text { of friends I have and the strength of those } \\
\text { relations. }\end{array}$ & 2.89 & 0.793 & Moderate \\
\hline 10 & $\begin{array}{l}\text { Social media would contribute to my } \\
\text { participation in certain public social } \\
\text { events, such as contests, exhibitions, or } \\
\text { initiatives, if they were announced in } \\
\text { these websites beforehand. }\end{array}$ & 2.86 & 0.780 & Moderate \\
\hline 11 & $\begin{array}{l}\text { Social media allows me chances to strengthen } \\
\text { my existing networks by engaging in } \\
\text { thoughtful discussions. }\end{array}$ & 2.75 & 0.430 & Moderate \\
\hline 12 & $\begin{array}{l}\text { Social media allows me to revive and } \\
\text { strengthen my old social relations with } \\
\text { colleagues, relatives, or friends. }\end{array}$ & 1.72 & 0.690 & Low \\
\hline & Overall & 3.64 & 0.191 & Moderate \\
\hline
\end{tabular}

To identify the social benefits of using social media based on disability, computational averages, and standard deviations were calculated, as illustrated in Table 3. This table shows apparent differences in the means of perceived benefits resulting from social media use according to the student's disability type.
Table 3. Descriptive statistics of perceived social benefits of social media use (by disability type)

\begin{tabular}{ccc}
\hline Disability & M & SD \\
\hline Auditory & 3.64 & 0.202 \\
$\quad \begin{array}{c}\text { Visual } \\
\text { Physical and } \\
\text { Health }\end{array}$ & 3.61 & 0.168 \\
The & 3.69 & 0.195
\end{tabular}

The one-way ANOVA was conducted to identify the significance of this difference, as shown in 
Table 4. Differences in the perceived benefits resulting from social media websites by students with different disabilities were not statistically different, $\mathrm{F}(2,173)=2.23, \mathrm{p}=.111$.

Table 4. Results of ANOVA on the significance of perceived social benefit differences (by disability).

\begin{tabular}{cccccc}
\hline Source & df & SS & MS & F & P \\
\hline $\begin{array}{c}\text { Between } \\
\text { Groups }\end{array}$ & 2 & 0.162 & 0.081 & 2.226 & 0.111 \\
$\begin{array}{c}\text { Within } \\
\text { Groups }\end{array}$ & 173 & 6.279 & 0.036 & & \\
Total & 175 & 6.441 & & &
\end{tabular}

To determine the impact of electronic communication time on the level of perceived benefits of using social media, the statistical averages and standard deviations of the perceived benefits of social media use by students with disabilities were calculated according to the duration of the electronic communication spent daily, as shown in Table 5. This table shows statistically significant differences in the means of the perceived benefits from social media use by university students with disabilities per the electronic communication duration variable.

Table 5. Descriptive statistics on perceived social benefits resulting from social media use (by the duration of use)

\begin{tabular}{ccc}
\hline Duration & M & SD \\
\hline $\begin{array}{c}\text { Less than } 1 \\
\text { hour }\end{array}$ & 3.64 & 0.202 \\
\hline to 3 hours & 3.61 & 0.168 \\
$\begin{array}{c}\text { More than 1 } \\
\text { hour }\end{array}$ & 3.69 & 0.195 \\
\hline
\end{tabular}

To identify the significance of these differences, one-way ANOVA was used, as shown in Table 6. This resulted in statistically significant differences in the perception of the benefits of social media use by university students with disabilities, F $(2,173)=26.14, \mathrm{p}<.001$.

Table 6. Results of ANOVA on the significance of perceived social benefits differences (by the duration of use)

\begin{tabular}{llllll} 
Source & df & SS & MS & F & P \\
\hline
\end{tabular}

\begin{tabular}{cccccc|}
\hline $\begin{array}{c}\text { Between } \\
\text { Groups }\end{array}$ & 2 & 1.495 & 0.747 & 26.139 & 0.000 \\
$\begin{array}{c}\text { Within } \\
\text { Groups }\end{array}$ & 173 & 4.946 & 0.029 & & \\
\hline Total & 175 & 6.441 & & & \\
\hline
\end{tabular}

To identify the significance of the differences of these social implications, the Scheffe's Test for the post-comparisons was conducted, as shown in Table 7. Statistically significant differences were found in social media usage based on the daily electronic communication period. Higher perceived benefits were found for students who used social media more than 3 hours a day.

Table 7. Results of Scheffe's test for postcomparisons of perceived social benefits from social media use

\begin{tabular}{lcccc}
\hline Duration & SD & (1) & (2) & (3) \\
\hline $\begin{array}{c}\text { (1) Less } \\
\text { than 1 }\end{array}$ & 3.55 & & - & - \\
hour & & & $0.24597^{*}$ & $0.17501^{*}$ \\
$\begin{array}{c}\text { (2) 1 to 3 } \\
\text { hours }\end{array}$ & 3.62 & $0.24597^{*}$ & & \\
$\begin{array}{c}\text { (3) More } \\
\text { than 3 } \\
\text { hours }\end{array}$ & 3.80 & $0.7501^{*}$ & & \\
\end{tabular}

\section{Discussions}

According to the findings, students with disabilities at the University of Jordan rate social media, on average, as providing a moderate level of social benefits for them. The highest level of benefits was increased opportunities to expand relationships, meet new friends, and strengthen connections between persons with disabilities and individuals with similar concerns. The results of this current study expand upon those of Ellison et al. (2014) and Al-Zboun and Abu Sablik (2014), who found that the most significant social impact of social media usage was attributable to the identification of new friends. Consistent with the uses and gratification theory, those students who spent more time on social media sites rated them as affording higher levels of a benefit than those who spent less time on these sites. The university students attributed a lower social media level to reviving old social relations with relatives or friends. The reason for this is unclear. These relationships were already strong and did not need 
to be revived or that the students were not interested in reviving them. This result contradicts the results of studies by Al-Zboun and Abu Sallik (2014) and Young (2011), which indicated that social networking sites revive old friendships and reinforce existing ones by supplementing traditional communication forms. Besides, the present study's findings did not align with those of Badr (2015), who reported the presence of positive or happy feelings of social media site users when connecting with old friends. Statistically insignificant differences were found in the perceived level of social media use benefits by students with disabilities at Jordan University based on disability type. These findings support Heasley (2010) results, who did not find any differences in social networking users' implications based on disability type. Other researchers have examined the number of times students with disabilities spend on social media sites and postulate that these sites afford opportunities to build social networks and vent social and physiological pressures (Abdul Hamid, Imam, \& Aziz; 2015; Al-Ahmari (2011; Almasri 2010). This may be particularly so for those

\section{Conclusion}

In light of the present study results, the researchers recommend that faculty and staff encourage the formation of electronic learning groups where students with and without disabilities collaborate on course projects and assignments. By minimizing communication and access barriers, such collaborations can increase opportunities for students with disabilities to engage in the learning exchanges, master course content actively, and demonstrate their capabilities. In addition, faculty and staff are encouraged to develop programs that help students with and without disabilities examine their social media use patterns, including time spent, sites used, site content, and purpose of usage. Consideration needs to be given to the advantages and the disadvantages stemming from the use or over the use of electronic media.

There is a vital need to conduct additional studies that examine the impact of social media platforms students whose physical, health, visual, or auditory disability results in significant social barriers that prevent them from communicating in person with others or choosing to communicate with them. The studies vary in the amount of time the participants report that they spent on social media each day. For example, Abdul Hamid et al. (2015) indicated that $46 \%$ of their participants spent one to two hours daily communicating electronically. Almasri (2010) stated that $30 \%$ of social media site users spent less than an hour each day communicating electronically. AlAhmari (2011) indicated that the study participants communicated electronically between three to four hours daily. Such time differences may result from the variance in the participants' demographics across the studies and from the selfreport versus time sample data collection methods. Though not examined in these studies, what is essential is whether there is an inverse relationship between the time spent on electronic communication versus face-to-face communications.

and content on students' lives with and without disabilities. Current popular sites include Facebook, Twitter, Instagram, and WhatsApp websites. Students in the Levant countries use Facebook more frequently, whereas people in the Arabian Gulf countries use Instagram more frequently. Beyond investigating the perceived benefits of social media, an in-depth analysis of the content of and targeted audiences for these sites is necessary to understand how access to knowledge is being affected, information is being manipulated, and cultures are being changed. In light of the current controversy regarding the misappropriation of personal data on social media platforms, studies also need to be conducted about the potential increase risk for victimization of people with disabilities. Finally, studies are needed to investigate the accessibility level of social media websites and develop technology solutions to those barriers that restrict usage by people with disabilities.

\section{Acknowledgement}

The authors of this study have received no funds to conduct this research; moreover, the authors 
have no conflict of interest. Indeed, the authors are very grateful to reviewers for their time and constructive suggestions to improve this article.

\section{References}

[1] A'abed, Z. (2012). The role of social media sites in mobilizing Palestinian public opinion toward social and political change. An-Najah National University Research Journal, 26(1). Nablus, Palestine.

[2] Abbas, S. (2017). The use of Facebook and its reflections on citizenship values. Journal of Media \& Communication Studies, (9), 136-155. Konoz Al-Hikma Publishing: Algeria.

[3] Abdul Hamid, I., Imam, W., \& Aziz, S. (2015). Deaf children's use of social media websites and the resulting gratifications thereof. Childhood Studies, 18(68), 103119.

[4] Abu Al-Robb, M. (2015). The degree of benefit of social media websites on the disabled. Psychoeducational Sciences Journal, 16(1), 167-292.

[5] Abu Ghoaleh, S. (2017). Uses of smartphone social media applications for the visually disabled and respective achieved benefits (Unpublished master's thesis). Islamic University of Gaza, Gaza, Israel.

[6] Abu Own, M. (2007). Effectiveness of Ibsar and Virgo program use on gaining internet-usage skills for blind students of the Islamic University (Unpublished master's thesis). Islamic University of Gaza, Gaza, Israel.

[7] Abu S'aileek, D. (2012). Effects of social media on university students' trends in Jordan and their proposed role in the development of a balanced personality (Unpublished doctoral dissertation). University of Jordan, Amman, Jordan.

[8] Ahmad, M. (2011). Emergence and development of communication technology and its relationship to dialogue:
Future vision. Ibn Tofail University, Kenitra, Morocco.

[9] Al-Ahmar, A. (2011). Reasons for social media website use for university youth: Field study on the students of Imam Mohammad Bin Saud Islamic University (Master's thesis). Imam Mohammad Bin Saud Islamic University, Riyadh, Saudi Arabia.

[10] Al-Alami, L. (2011). Presence on social media websites and its effects on improving political awareness of AnNajah National University students. AnNajah National University, Palestine.

[11] Al-Fadhil, S. (2013). Dimensions of social media network use of Saudi youth: Field study on a sample of male and female students of King Saud University, Riyadh (Master's thesis). King Saud University, Riyadh, Saudi Arabia.

[12] Al-Hayes, A. W. (2015). Social effects of social media use on certain aspects of young persons. Social Affairs, UAE, 32(126), 122-177.

[13] Al-Jallad, H. (2014). Reflections of the use of social media websites on the spread of violence phenomenon among female university students. Field study on Zagazig University Students. Educational \& Social Studies, Egypt, 20(4), 913-978.

[14] Al-Masri, N. (2010). University students' uses of social media websites and their effects on other forms of media. From the Conference of Media and Social Transformations, Faculty of Information. Yarmouk University, Irbid, Jordan.

[15] Al-Obaid, I. (2015). Effects of social media networks on the Faculty of Education students at Qassim University, as viewed by them: Twitter as a model. Psychoeducational Sciences Journal, 8(3), 641-745. Qassim University, Buraydah, Saudi Arabia.

[16] Al-Oteibi, J. (2008). Impact of Facebook on the students of official universities (Unpublished master's thesis). King Saud University, Riyadh, Saudi Arabia. 
[17] Al-Saqer, T., \& Hendawi, G. (2016). Factuality of social media website use as viewed by adolescent students and its effects on their behavior as viewed by their parents. Mutah Journal of Research \& Studies, 31(2), 41-76.

[18] Al-Zboun, M., \& Abu, S. D. (2014). Social and cultural effects of social media networks on children during the stage of adolescence in Jordan. Jordan Journal of Social Sciences, 7(2), 225-251.

[19] Asuncion, J., Budd, J., Fichten, C., Nguyen, M., Barile, M., \& Amsel, R. (2012). Social media use by students with disabilities. Academic Exchange Quarterly, 16(1), 30-35.

[20] Awawdeh, N. (2013). The psychological and social effects of social media network use (Facebook) on Norther Palestine students in light of certain variables (gender, academic level and achievement) (Unpublished master's thesis). Yarmouk University, Irbid, Jordan.

[21] Bader, A. (2015). Cultural, social and psychological effects of the Gulf youth's use of social media networks. Journal for Media \& Communication Studies, (28), $10-41$.

[22] Boyd, D., \& Ellison, N. (2008). Social network sites: Definitions, history, and scholarship. Journal of ComputerMediated Communication, 13(2), 210-230.

[23] Ellison, N., Vitak, J., Gray, R., Lampe, C. (2014). Cultivating social resources on social network sites: Facebook relationship maintenance behaviors and their role in social capital processes. Journal of Computer-Mediated Communication, 19(4), 855-870.

[24] Heasley, S. (2010). Social networks opening doors for people with disabilities. Retrieved from https://www.disabilityscoop.com/2010/09/ 07/social-networks-disability/10095/

[25] Jaeger, P. (2009). Developing online community accessibility guidelines for persons with disabilities and older adults.
Journal of Disability Policy Studies, (1), 2055-2063.

[26] Junco, R. (2012). The relationship between frequency of Facebook use, participation in Facebook activities, and student engagement. Computers \& Education, 58, 162-171.

[27] Kardash, F. (2005). Arab social media and uses among the Arab communities. DarEl-Fikr Al-Arabi, Cairo.

[28] Katrina, M., \& Nessa, O. (2010). The experiences of people with learning disabilities on social networking sites. British Journal of Learning Disabilities, 42(1), 1-5. doi:10.1111/bid.12001

[29] Lewthwaite, S. (2011). A study of student experiences of disability and social networks on campus in higher education (Unpublished doctoral dissertation). University of Nottingham, Nottingham, United Kingdom.

[30] Makkawi, H., \& Al-Sayyid, L. (2010). Communication and its modern theories. Dar Al Masriah Al Lubnaniah: Cairo, Egypt.

[31] Melhem, S. (2017). Measurement and evaluation in education and psychology (8th ed.). Dar Al Masriah: Amman, Jordan.

[32] Paul, J., Baker, A., Hope, M., \& Cochran, J. (2012). Effect of online social networking on student academic performance. Computers in Human Behavior, 28(6), 2117-2127.

[33] Soderstrom, S., \& Ytterhus, B. (2010). The use and non-use of assistive technologies from the world of information and communication technology by visually impaired young people: A walk on the tightrope of peer inclusion. Disability \& Society, 25(3), 303-315.

[34] Urista, M., Dong, Q., \& Day, K. (2014). Explaining why young adults use MySpace and Facebook through uses and gratifications theory. Human Communication, 12(2), 215-229. 
[35] www.Facebook.com.

[36] Yang, C. C., \& Brown, B. (2013). Motives of using Facebook, patterns of Facebook activities, and late adolescent's social adjustment to college. Journal of Youth \& Adolescence, 42(3), 403-416.

[37] Young, K. (2011). Social ties, social networks and the Facebook experience. International Journal of Emerging Technologies \& Society, 9(1), 20-34. 